\title{
Immobilized enzymes: a comprehensive review
}

Mohammad Rafiq Khan*

\begin{abstract}
Background: This article is a comprehensive review of the events recorded in the history of enzymology from twentieth century to the recent work of author's groups on different biochemical aspects of the immobilized enzymes. The review differs from those presented before on the basis that it is not limited to one or few aspects. It extends its spectrum to a large number of aspects from the definition to biomedical applications of immobilized enzymes.

Main body: The author and his associates have proposed modification of classification of immobilized enzymes by Enzyme Engineering Conference 1971. His groups have worked on cell bound proteases of medicinal seeds and have given them the name of "naturally immobilized enzymes". Thus, the author proposes that the enzymes may be basically classified into "naturally immobilized enzymes" and "artificially immobilized enzymes". The artificially immobilized enzymes may be further sub-classified as done in 1971.

Conclusion: The classification suggested above sounds logical and thus acceptable to the author and his associates. The author and his associates also suggest some applications on the basis of their results on naturally immobilized enzymes.
\end{abstract}

Keywords: Comprehensive, Review, Immobilized, Enzymes, Naturally immobilized artificially immobilized

\section{Background}

The "immobilized enzymes" have been defined as "enzymes physically confined or localized in a certain defined region of space with retention of their catalytic activities, and which can be used repeatedly and continuously" (Brena et al. 2006, 2013). The immobilization constitutes a system whose major components are the enzyme, the matrix with which the enzyme binds to support and to the mode of attachment. ranging from reversible physical adsorption and ionic bonds to stable covalent linkages. These linkages are established via amide, ether, thio ether, or carbamate bonds, resulting into changes in enzyme properties: catalytic activity or thermal stability. These changes form the basis of a large number of applications in different fields. The stabilization at the molecular level has been extensively reported,

\footnotetext{
*Correspondence: drrafiq@lahoreschool.edu.pk; khanmr1939@yahoo.com
} Lahore School of Economics, Lahore, Pakistan and there is encountered highly significant research activity in the field of enzyme immobilization and applications of immobilized enzymes.

An alternative to the enzyme immobilization is the immobilization of the whole cells with enzymes inside or outside to constitute whole cell system. Here, contrary to "enzyme immobilization system" in which an enzyme is attached to a solid support, the target cells are immobilized in a whole cell system. Thus, the cell immobilization has been defined as "an entrapment or localization of living cells to a certain region of space with preservation of their metabolic (anabolic + catabolic) activity translating into improvement of the efficiency of the cultures (Tosa et al. 1969a)". The techniques that took start with immobilization of enzymes in 1970 have been continuously applied to immobilize microbial cells of both plants and animals. Microbial enzymes have been classified into extracellular and intracellular enzymes. The extracellular enzymes are excreted from the cells into the culture medium, while intracellular enzymes are retained in the 
cells during the fermentation. These enzymes may be the precursors of the extracellular enzymes. The intracellular enzymes as components of cells (Immobilized cells) are successfully applied in a number of fields: "biotechnology, genetic engineering and enzyme engineering".

Enzymes being the "biological catalysts produced by living cells" that catalyze all biochemical reactions in the living body are the part and parcel of human life and thus have also found many applications in different fields: medical, agriculture, industry, biochemical research and others. Because the enzymes are thermoslabile, they have presented the problem of preservation of their life for their prolonged use overtime. Thus, the research to that end has been in progress since Nelson and Griffin (1916) observed that an enzyme in waterinsoluble form shows catalytic activity. This was based on their research work on invertase extracted from yeast adsorbed on charcoal, which showed the same activity as did the native enzyme. Sato and Tosa (2002) reviewed the brief history of methods for the immobilization of the enzymes from that point of time. As reported by these reviewers, Sumner (1946) had observed "that urease from jack bean became water insoluble on standing in 30\% alcohol and sodium chloride for 1-2 days at room temperature and the water-insoluble enzyme was active". That is how the showing of activity by enzymes in water-insoluble state formed the basis of immobilization. The review states that "the first attempt to immobilize an enzyme to improve its properties for a particular application was not made until Grubhofer and Schleith (1953) immobilized enzymes such as carboxypeptidase, diastase, pepsin, and ribonuclease by using diazotized polyaminopolystyrene resin". Of course, some experiments of practical significance were conducted by some researchers. Immobilization of physiologically active proteins was conducted by Micheel and Ewers (1949), and preparation of immobilized antigen by attaching albumin to diazotized p-aminobenzylcellulose was accomplished by Campbell et al. (1951). From 1953 to 1960, appeared a number of reports on the preparation and application of immobilized antigens and antibodies that were applicable to immobilized enzymes. In 1960s, many research articles appeared in this context. The articles such as authored by Atara and Katchaklaski (1961) and Katzir-Katchalski et al. (2000) can be cited as examples. These researchers conducted a number of studies on new immobilization techniques and on different properties of immobilized enzymes. Tosa et al. (1969b) succeeded in standardization of a continuous industrial process for the optical resolution of DL-amino acids using immobilized aminoacylase. This, being the first industrial application of immobilized enzymes at the global level, acted as a big boost for holding of the first Enzyme Engineering
Conference (1971). The predominant theme of this conference was "immobilized enzymes". The term "immobilized enzyme" was recommended at the Conference. Before that time, "various terms such as "water-insoluble enzyme", "trapped enzyme", "fixed enzyme", and "matrixsupported enzyme" were in use (Rani 2012). "The functional groups involved in enzyme immobilization were identified as under:

1. Free amino and carboxyl groups

2. Sulfhydryl group of cysteine

3. Imidazole group of histidine

4. Phenolic groups and hydroxyl groups of serine and threonine"

An intensive research was conducted on techniques of immobilization, and the results led to the requisites highlighted in following points for purposeful immobilization:

a. The functional groups in composition of the active center should not be involved during the process of immobilization of the enzyme. Otherwise the enzyme activity may be lost due to inactivation.

b. As the tertiary structure of enzyme protein is maintained by relatively weak binding forces such as hydrophilic, hydrophobic and ionic, it is imperative to carry out immobilization reaction under mild conditions.

Keeping in view the brief history of progress in the field of "Immobilized Enzymes" and making some points to highlight the background for writing a comprehensive review, the overall review has been split into the following parts with reference to different aspects of the subject:

A. Classification of the immobilized enzymes

B. Techniques of immobilization

C. Change in the properties of enzymes after Immobilization

D. Basis of extensive research on immobilized enzymes

E. Applications of immobilized enzymes

\section{Main text \\ Classification of immobilized enzymes}

The enzymes were first classified into two groups: "native enzymes" and "modified enzymes". The immobilized enzymes belonged to the class of modified enzymes and are currently further divided into two groups: "entrapped 
immobilized enzymes" and "bound immobilized enzymes".

\section{Entrapped immobilized enzymes}

"Entrapped enzymes are those enzymes that can be entrapped in a semi-permeable gel or enclosed in a semi-permeable polymer membrane". For example, glucoamylase is entrapped by polyacrylic acid and invertase by polyvinyl alcohol (Zdarta et al. 2018)".

"Entrapped enzymes are further divided into two sub-classes:

(a) Matrix entrapped enzymes Matrix-entrapped enzymes are those which are entrapped within the interstitial spaces of cross-linked water-insoluble polymers, i.e., within a gel. For example, alcohol dehydrogenase is entrapped within polyacrylamide and invertase is entrapped within polyethylene glycol polymer (Godbole et al. 1980).

(b) Micro-encapsulated enzymes These are the enzymes, which are enclosed within the semi-permeable polymer membranes.

\section{Bound immobilized enzymes}

Bound immobilized enzymes are also further sub-divided into two classes: adsorbed bound immobilized enzymes and covalently bound immobilized enzymes.

Adsorbed bound immobilized enzymes The adsorbed immobilized enzymes are those which are immobilized by binding with an adsorbent such as activated charcoal and micro-glass beads (Science, Direct)".

\section{Covalently bound immobilized enzymes}

The covalently bound immobilized are those which are immobilized by attachment to a matrix through a covalent chemical linkage.

The author and his associates, in the light of their research in the field of immobilized enzymes, have proposed modification of classification of immobilized enzymes by Enzyme Engineering Conference (1971) because his groups have worked on cell bound proteases of medicinal seeds and have given them the name of "Naturally Immobilized Enzymes" (Khan and Bukhari 2008a, b; Khan et al. 2008). Thus, the author has proposed that the enzymes should be basically classified into "naturally immobilized enzymes" and "artificially immobilized enzymes". The latter should be further subclassified as done in 1971. That sounds logical and thus acceptable to the author and his associates (Khan 2021).
The author and his associates appreciate without any reservation the spectrum of applications of immobilized enzymes and breaking the news that the spectrum being broad, the field of immobilized enzymes deserves a close attention. It will open new vistas for broadening the spectrum of applications for the benefit of future generations. This encourages the author and his associates to give some suggestions based on the results of their research particularly on naturally immobilized enzymes on the basis that "Whatsoever is natural is safer to use as medical treatment".

\section{Changes in properties of enzymes after immobilization}

Immobilization translates into certain changes in the characteristics of the enzymes, which form the basis for the determination of the applications of immobilized enzymes and for the explanation of structure and function, relationship between the enzyme and substrate, mechanics of enzymatic action, etc. Two factors are responsible for change of the enzyme characteristics: structural changes of enzyme itself and changes in physical and chemical characteristics of matrices used for immobilization.

Below are outlined the main properties of the enzymes that may or may not undergo a change after immobilization.

Substrate specificity When enzymes are immobilized, their activity often decreases and the substrate specificity also undergoes a change accordingly, for example, when enzymes such as proteases and amylases acting on certain substrates having higher molecular weight are immobilized by carrier binding method. For example, in peptide binding or diazo binding, significant changes of substrate specificity have been encountered.

It has been observed that "when an enzyme is immobilized using a water-insoluble polymer carrier, the enzyme activity toward substrates of higher molecular weight is markedly reduced due to steric hindrance which obstructs the approach of the substrate to the enzyme molecule (Zhong et al. 2014)". However, the activity of the immobilized enzymes toward substrates of low molecular weight is not significantly changed, because the substrate can easily approach the enzyme (Science Direct Online).

Immobilized enzymes show better thermal and storage stability than the free enzymes. Increase in $\mathrm{Km}$ value only about 1.25 times has been reported, and enzyme activity behavior to $\mathrm{pH}$ and temperature function has been reported (Waterhouse and waterhouse 2020).

Temperature dependence of enzymatic reactions The catalytic activity of enzymes is dependent upon temperature, as it is observed in case of ordinary chemical catalysts. The activity is lost at temperature above a certain limit due to the denaturation of enzyme protein. Changes 
in the optimum temperature of the enzymatic reaction after immobilization occur in some cases. The optimum temperatures of immobilized enzymes were observed to be many times higher than those of native enzymes in case of trypsin and chymotrypsin immobilized by peptide binding with CM cellulose (Homaei et al. 2013).

There are, of course, many reports that "no change of optimum temperature occurs after immobilization. Examples are chymotrypsin immobilized with $\mathrm{CNBr}-$ activated cellulosic membrane, trypsin immobilized with CNBr activated agarose, etc. (Singh et al. 2013)".

Markoglou and Wainer (2003) studied the effect of immobilization on the thermal stability of phenylethanolamine $N$-methyltransferase (PNMT), and the immobilized enzyme was observed to exhibit increase in thermal stability. The initial enzyme activity was lower for the immobilized PNMT, relative to the non-immobilized enzyme, and it remained comparatively stable over the range of experimental temperature. In their opinion, "increased stability may be a result of the fact that immobilization limits the thermal movement of the enzyme at higher temperatures. As a result, thermal denaturation may not occur at higher temperatures with an immobilized enzyme. Thermostable enzymes allow for higher reaction rate, lower diffusional restrictions, increased stability and greater yields".

Homaei et al. (2013) have updated the techniques of immobilization compared to free enzymes in solution and reported that the immobilized enzymes are "more robust and more resistant to environmental changes". In their opinion, the "heterogeneity of the immobilized enzyme systems allows an easy recovery of both enzymes and products, multiple re-use of enzymes, continuous operation of enzymatic processes, rapid termination of reactions, and greater variety of bioreactor designs".

pH dependence of the enzymatic action The enzymes are proteinous in nature, and thus, their catalytic activity is markedly affected by the $\mathrm{pH}$ of the aqueous medium. Changes in activity to $\mathrm{pH}$ behavior caused by immobilization of enzymes help in the understanding of the structure-function relationship of enzyme protein. Suzuki and Ozawa (2014) prepared water-insoluble yeast invertase by binding native invertase with DEAE-cellulose and compared some of its characteristics with that of native enzyme and also described the continuous hydrolysis of sucrose by its use. "The activity of bound invertase corresponded to about half at $\mathrm{pH} 3.4$ with shift to $\mathrm{pH} 2$ "after binding when compared with the maximum activity of free form and it could hydrolyze sucrose into invert sugar perfectly". Stability of bound invertase to temperature, of course, was slightly less compared to that of free invertase at $\mathrm{pH}$ 5.2".
There are many cases of shift in optimum $\mathrm{pH}$ without showing any change in $\mathrm{pH}$ activity curve after immobilization. "The optimum $\mathrm{pH}$ of amino acylase immobilized by ionic binding with DEAE cellulose or DEAE sephadex shifted 0.5 to $1.0 \mathrm{pH}$ unit to the acid side from the optimal $\mathrm{pH}$ of the native enzyme. Similar shifts in optimum $\mathrm{pH}$ have been encountered with invertase and ATP, D-aminase immobilized by ionic binding with DEAE cellulose and NADH dehydrogenase immobilized by cross-linking using glutaraldehyde (Homaei et al. 2013). "The current demand of the world's biotechnological industries is enhancement in enzyme productivity and development of novel techniques for increasing their shelf life. These requirements are inevitable to facilitate large-scale economic formulations. Enzyme immobilization provides an excellent base for increasing availability of enzyme to the substrate with greater turnover over a considerable period of time. Several natural and synthetic supports have been assessed for their efficiency for enzyme immobilization. Nowadays, immobilized enzymes are preferred over their free counterparts due to their prolonged availability that curtails redundant downstream and purification processes. Future investigations should endeavor at adopting logistic and sensible entrapment techniques along with innovatively modified supports to improve the state of enzyme immobilization and provide new perspectives to the industrial sector (Datta et al. 2013)".

Hassan et al. (2019) conducted covalent immobilization of glucoamylase on the chemically activated surface of $\mathrm{k}$-carrageenan. The authors reported that the immobilized enzyme showed enhancement in temperature profile as the optimal temperature for the free enzyme was $60{ }^{\circ} \mathrm{C}$, which increased to the range of $60-80{ }^{\circ} \mathrm{C}$ : broader range and stability in acidic conditions. "The apparent $\mathrm{Km}$ of immobilized enzyme, $147.46 \mathrm{mM}$, became higher than $\mathrm{Km}$ of the free one, $110 \mathrm{mM}$ and the maximum reaction velocity ( $\max$ ) values for the immobilized enzyme decreased from 2.28 to $1.11 \mu \mathrm{mol} \mathrm{min}^{-1}$. The immobilized enzyme could be reused and kept its activity (100\%) till 11 successive cycles". The conclusion was that the economic and biotechnical benefits of enzyme immobilization, particularly with reference to the number of enzyme reuses, would open the possibility of increase in different industrial applications.

There are also some reports that both shifts of optimum $\mathrm{pH}$ and the change of $\mathrm{pH}$ activity curve occur as a result of enzyme immobilization. An important example is of glucoamylase immobilized by alkylation with dichlorotriazinyl cellulose. The $\mathrm{pH}$ shifted to the acid side and the $\mathrm{pH}$ activity became narrow compared with that of the native enzyme (Homaei et al. 2013). 
"Some immobilized enzymes show no shift of optimum $\mathrm{pH}$ but do exhibit changes of $\mathrm{pH}$ activity curve. In case of $\beta$-fructo furanosidase immobilized by diazo binding with poly amino polystyrene, for example, the optimum $\mathrm{pH}$ did not shift, but the pH activity curve became narrow (Filipusson and Hornby 1970)".

Activation energy of immobilized enzymes Some enzymes do not undergo a change in the energy of activation. Some undergo an increase and some a decrease after immobilization. The activation energies of some immobilized enzymes are almost the same as those of the corresponding native enzymes. Examples may be invertase immobilized by physical adsorption on activated carbon, asparaginase and invertase immobilized by ionic binding with DEAE cellulose.

The activation energies of amino acylase immobilized by ionic binding with DEAE cellulose and DEAEsephadex have been reported to increase compared to those of the native enzyme. The decreases of activation energy have also been observed. For example, "the Energy of Activation $\left(E_{a}\right)$ of invertase from NOVO Nordisk immobilized in controlled pore silica particles by covalent binding with the silane-glutaraldehyde method. was found as $\mathrm{pH}$ dependent. It gave for free invertase, $\mathrm{E}_{\mathrm{a}}=7.0$ and $6.86 \mathrm{kcal} / \mathrm{mol}$ at $\mathrm{pH} 5.0$ and 5.5 , respectively, whereas for the immobilized enzyme, $E_{a}=6.55$ and $5.93 \mathrm{kcal} / \mathrm{mol}$ at $\mathrm{pH} 4.5$ and 5.0 , respectively, was found to be a function of $\mathrm{pH}$, giving for free invertase, $\mathrm{E}_{\mathrm{a}}=7.0$ and $6.86 \mathrm{kcal} / \mathrm{mol}$ at $\mathrm{pH} 5.0$ and 5.5 , respectively, whereas for the immobilized enzyme, $E_{a}=6.55$ and $5.93 \mathrm{kcal} / \mathrm{mol}$ at pH 4.5 and 5.0, respectively (Bergamasco et al. 2000)".

Stability An increase of stability of enzymes after immobilization has been encountered in many cases. The enhancement of stability leads to some advantages for the industrial applications of immobilized enzymes and is an important index of the feasibility of enzymes for specific applications. Different kinds of stabilities are briefly outlined below:

Stability towards regents Immobilization of enzymes causes changes in the stability of enzymes towards different reagents. Increase in stability towards protein denaturing agents or enzyme inhibitors has been encountered for some immobilized enzymes. For instance, immobilized amino acylase and immobilized trypsin are not inhibited by urea. Increased resistance towards inhibitors has also been reported for some immobilized enzymes. Immobilized trypsin prepared by peptide binding and carrier-cross-linking with CM-cellulose azide has been said to become resistant to trypsin inhibitor. It sounds quite convincing that the approach of high molecular weight trypsin inhibitor to the immobilized enzyme is interrupted by steric hindrance.

Levitsky et al. (1998) reported that the proteolytic enzymes immobilized by adsorption on a solid support were widely used for synthetic reactions in low water systems. However, stability of such products had to be optimized to avoid reversible and irreversible inactivation of enzyme by organic solvent. Immobilization of enzyme, previously involved in non-covalent complex with polyelectrolyte, could be a possible way to suppress inactivation processes. In the research work reported here, non-covalent complex between $\alpha$-chymotrypsin and polycation Polybrene was immobilized on Celite and the stability of the resulted biocatalyst against irreversible inactivation by organic solvents as DMSO, DMFA and $\mathrm{AcN}$ at $30^{\circ} \mathrm{C}$ was investigated. It was observed that the complexation with Polybrene could result into either stabilization or destabilization of enzyme depending on type and concentration of organic co-solvent. "Maximal protective effect, defined as ratio of half-life times of enzymes, immobilized in/ out of complex with Polybrene, was about 50-fold for inactivation by dry DMFA and 30-fold for inactivation by dry AcN and 20\% solution of DMSO".

Stability towards proteolytic enzymes "In enzymatic reactions using crude enzyme preparation, inactivation of the enzyme is often encountered to accelerate by contaminating proteolytic enzymes. In some cases, resistance to various proteolytic enzymes is increased by immobilization (Kilbinov, On-line)".

In case of proteolytic enzymes such as trypsin and papain, the stability is increased by a decrease of catalytic activity towards substrates of high molecular weight due to steric hindrance because of reduction of the extent of autolysis.

Heat stability "The catalytic activity of enzymes increases with elevation of temperature, as it happens in case of chemical catalysts. However, as enzymes are proteins and are generally heat sensitive, the enzymatic reactions cannot be carried out at high temperature. If the heat stability of enzymes is increased by immobilization, the potential utilization of such enzymes will be extensive".

Operational stability "The operational stability of immobilized enzymes is one of the most important factors affecting the success of industrialization of the immobilized systems. A column of immobilized papain prepared by carrier cross-linking with porous glass retained full initial activity after 35 days of continuous operation at $45^{\circ} \mathrm{C}$ with casein solution has been reported by Freeman and Lilly (1998)". 


\section{Kinetic constants}

Conformational changes of the enzyme protein may take place after immobilization (Hassan et al. 2019), and thus, the affinity between enzyme and substrate may also undergo a change. The authors have reported that little or no change occurs in Michaelis-Menten constant $(\mathrm{Km})$ that indicates the presence of affinity between enzyme and substrate after immobilization.

In some cases, "significant changes, say up to twofold magnitude occur. The $\mathrm{Km}$ value for trypsin immobilized by a polyanionic carrier ethylene maleic anhydride co polymer was determined using positively charged benzoyl $\mathrm{L}$-arginine amide as a substrate at various ionic strengths (Science Direct, Library)". It is also reported that "Km for the immobilized enzyme decreased to $1 / 10$ th that of the native enzyme at lower ionic strength but approached that of native enzyme at higher ionic strength". Thus, "the change in $\mathrm{Km}$ value was considered to be caused by electrostatic attraction between the carrier and the substrate". Some experiments have also shown that "the $\mathrm{Km}$ values measured for asparaginase microencapsulated in nylon or polyurea membrane and immobilized by entrapping in poly acrylamide gel become greater than those of native enzyme by twofold magnitude". In an earlier report by Mori et al. (1972), an astonishingly high value of increase that is about 200 times in $\mathrm{Km}$ for asparaginase trapped in poly acrylamide microcapsule has been reported.

\section{Techniques of immobilization}

Methods for enzyme immobilization have been basically classified into three categories as outlined below.

1. Carrier-binding method In this method, the linking of enzymes is accomplished with water-insoluble carriers: polysaccharide derivatives, synthetic polymers, and porous glass.

2. Cross-linking method This method involves the intermolecular cross-linking of enzymes by bi-functional or multifunctional reagents such as glutaraldehyde, bisdiazoben-zidine, and hexamethylene, diisocyanate.

3. Entrapping method Here the enzymes are incorporated into the lattice of a semipermeable gel or the enzymes are enclosed in a semipermeable polymer membrane: collagen, gelatin, cellulose triacetate, polyacryl-amide, and j-carrageenan, etc.

One of the methods being studied involves the immobilization of enzymes by trapping in certain active materials or by binding with specific matrices. The enzymes in the immobilized state are less subject to denaturation and thus can be preserved over time. Several techniques have been developed to prepare immobilized enzymes because they exhibit many advantages over enzymes in the solution state (Mohamad et al. 2015). An overview of technologies for enzyme immobilization and surface analysis techniques for immobilized enzymes has been presented by Biotechnology and Biotechnological Equipment (Mohamad et al. 2015). For instance, immobilization leads to ease of recoverability and reusability of the enzymes.

Proteolytic enzymes that hydrolyze and thus break down proteins into smaller units such as proteoses, peptones, amino acids can be immobilized on different materials. These can be subsequently applied for continuous hydrolysis of protein substrates. Enzymes are usually immobilized by binding them with some matrices filled in chromatographic columns and subsequently passing through them the buffered substrates and collection of products of hydrolysis eluting out of the column. Enzymes immobilized in this way may increase the stability of enzymes to thermal shocks and extremes of $\mathrm{pH}$. The enzymes, after immobilization, undergo certain changes in the spectrum of their activity. Fortunately, many enzymes remain significantly active after their immobilization. Thus, immobilization leads to ease of recoverability and reusability of the enzymes. Proteases break down proteins into smaller units that may recombine to yield different proteins essentially required by the organic body. This process of breaking and reforming is in operation continuously in living organisms. The process of breakdown of proteins by proteases into peptides, amino acids, etc. is called proteolysis. Although the observations about the action of proteolytic enzymes on proteins made the discovery of the cleavage of the peptide bond in the nineteenth century, still at that time there was no clear map of the mode of action of enzymes. Later, when it became known that the amino acids were linked by the peptide bonds in proteins, the experts paid full attention to understand the mode of action of theses enzymes on protein to utilize proteases on commercial scale. The proteases have also found extensive applications in medicine as cures of diseases such as stomach disorder, fistulas, hyperacidity and cramps. They are being extensively used as anti-inflammatory agents. They digest dead cells of skin's necrotic tissue and thus act as wound cleaners. Similarly, they are being widely applied as cleaners of contact lenses.

On the basis of the importance of proteases highlighted above, the proteases have been under extensive investigation in the past and, even, are currently being intensively studied, all over the world. The countries involved in this activity are USA, China, Australia and Japan and some developing countries including Pakistan. China, of course, is the leader to utilize plant proteases on commercial scale. Some significant reports have appeared 
which highlight the diversity of applications of proteases in Pakistan. Amino acids and other products of proteolysis have extensive applications in different fields. The mixture of amino acids can be transfused with the help of drips into the body of patients. The supply of these essential nutrients for the synthesis of structural and functional proteins, essentially required for the body, may be ensured. Amino acids may also be separated for use in Chemistry laboratories. There are also many other applications of amino acids. Considerable work has been carried in Pakistan to hydrolyze casein by proteases immobilized on different materials keeping in view the above-mentioned applications. An attempt was made to develop continuous proteolysis systems consisting of protease immobilized by combining with artificial and naturally occurring materials such as DEAE A-50 cellulose, Amberlite-50, Activated Charcoal (Khan and Talib 1986; Nawaz and Khan 2000). Later, the work was extended to the study of naturally immobilized proteases of vegetable origin such as Carum copticum, Allium sepa, Nigella sativa (Khan and Bukhari 2008a, b; Khan et al. 2008). The difficulty encountered was that there was also contained in the cells of the seeds the soluble protease component. Thus, the seeds were investigated for both soluble and immobilized proteases. The results, of course, revealed that the major component was the immobilized one, while soluble component was a minor one. This difference made a good ground for the study of naturally immobilized enzymes packed in chromatographic columns. Thus, the work was extended by the elution of soluble enzyme so that only the cell bond enzyme may react with the substrates.

The current demand of the world's biotechnological industries is increase in enzyme productivity and development of innovative techniques for increasing their shelf life. These requirements are essential to facilitate large-scale and economic formulations. Enzyme immobilization provides an excellent basis for increasing availability of enzyme to the substrate with greater turnover over a considerable period of time. Several natural and synthetic supports have been evaluated for their efficiency for enzyme immobilization. Nowadays, immobilized enzymes are preferred over their free counterparts due to their prolonged availability that curtails redundant downstream and purification processes. Future investigations should aim at adopting logistic and sensible entrapment techniques along with innovatively modified supports to improve the state of enzyme immobilization and provide new perspectives to the industrial sector. The reviews such as by Datta et al. (2013) and others have the focus on the development of immobilization techniques with regard to their application in industry.
A number of techniques have been developed to bring the enzymes in the immobilized state. While making the choice of techniques for enzyme immobilization, it is desirable that the native enzymes retain most of their catalytic activity in the immobilized state. To that end, it is essential that the enzyme retains its native structure and conformation as far as possible. Therefore, immobilization should be carried out under very mild and appropriately controlled conditions.

The change in catalytic activity of the enzyme during immobilization largely depends upon certain structural changes in its active centers. If the amino acid residues involved in the tertiary structure of the active center are altered, the catalytic activity may decrease. The decrease may be accompanied by the changes of enzymatic properties such as substrate specificity.

The functional groups involved in the enzyme immobilization are free amino, carboxylic and the active groups contributed by different amino acids such as sulphydryl (-SH) provided by cysteine), imidazole by histidine, phenolic, and hydroxyl by serine and threonine.

In order to retain most of the catalytic activity after immobilization of the enzyme, it is essential that the functional groups in the active center may not be involved in the reaction leading to the immobilization of the enzyme.

Keeping in view, the retention highlighted above and development of certain characteristics of the immobilized enzymes that qualify them for applications in industry, an intensive research has been conducted and many reviews have been documented. The number of methods has also expanded particularly at the sub-class level. Methods recently and currently applied for enzyme immobilization are sub-classified below. A brief description of each method is also given.

Carrier binding method This is the oldest enzyme immobilization method. In this method, "the immobilization is accomplished by physical or chemical bonding of the enzyme with an appropriate carrier. The carriers mostly used for immobilization are physical adsorbents such as coal, porous glass, polyacrylamide gel, etc. (Jesionowski et al. 2014)".

A lot of care is required while selecting of carriers as well as carrying out the binding technique. The selection of carrier depends on the nature of the enzyme itself with regard to the parameters: particle size, surface area molar ratio of hydrophobic groups and chemical composition of the carrier. The carrier binding methods may be further subdivided into three types.

A. Physical adsorption method The principle involved in this method is the physical adsorption of enzyme proteins on the surface of water-insoluble carriers. The physical adsorption causes little or no conformational change 
in enzyme molecule, which may lead to the destruction of its active center. The only disadvantage of this method is that the adsorbed enzyme may leak out of the carrier during its use as the binding force between the enzyme protein and the physical adsorbing carrier is weak. Usually employed as carriers are the inorganic materials: activated carbon, porous glass, acid clay, bleaching clay, alumina, silica gel, calcium phosphate, etc. Natural polymers such as starch and gluten have also been used.

The immobilization of invertase on charcoal was studied by Nelson and Griffin (1916). These workers observed that "the enzyme adsorbed on the activated carbon retained its catalytic activity towards sucrose. The immobilization of an enzyme lipoamide dehydrogenase by hydrophobic binding to a carrier has also been reported in literature (Lowe 1977). "The enzyme was immobilized by binding with carriers containing hydrophobic residues such as butyl or haxyl sepharose. It has been readily immobilized by using adsorbent containing tannin as a ligand". The tannin amino haxyl cellulose can be used for immobilization of many enzymes and the hydrophobic forces play an important role in this immobilization.

B. Ionic binding method This method is based on the principle of ionic binding of the enzyme protein to the water-insoluble carrier containing ion exchange residues (Krishnamoorthi et al. 2015).

Polysaccharides and synthetic polymers having ion exchange residues have been successfully used as carriers for ionic binding. This method causes little or no change of conformation in the structure of active site of the enzyme protein and thus yields the immobilized enzymes having high activity in many cases. The disadvantage of the method is that the leakage of the enzyme from the carrier may occur in substrate solutions of high ionic strength upon variation of $\mathrm{pH}$ of medium because of the weakening of the ionic forces.

The results of immobilization of the enzyme by ionic binding method are reported by Mitz (1956). He prepared immobilized catalase by passing the enzyme solution through a column packed with DEAE cellulose. Highly active and stable immobilized protease has been prepared using anion exchange carriers such as DEAE cellulose (Khan and Talib 1986). Ionic binding to the carriers has also been reported after infusing the change in enzyme protein by chemical modification. For example, anionic glucoamylase was modified to a polyanionic derivative by covalent bonding with a water-soluble polymer of ethylene and maleic anhydride (Goldstein et al. 1964).

C. Covalent binding method This method involves the binding of enzymes and water-insoluble carriers by covalent linkages (Hartmeier 2016). "The functional groups which take part in covalent binding of enzyme to the carrier are given below.

(i) $\alpha$ or 3-amino group

(ii) $\alpha, \beta$ or $\gamma$ carboxylic group

(iii) Sulfhydryl group

(iv) Hydroxyl group

(v) Phenolic group

These functional groups react with carriers containing reactive groups such as diazonium, isocyanide, halides and acid azide".

"The reaction conditions required for covalent binding are relatively complicated. The binding force between enzyme and carrier being strong, the leakage of the enzyme does not take place. This is an advantage of this method over physical adsorption and ion exchange methods". This method can be further classified into types given below on the basis of the nature of the reaction involved.

I. Peptide binding method: This method is based on the conformation of peptide bond between enzyme protein and water-insoluble carriers (Fu et al. 2011). In 1956, Brandenberger used a carboxychloride of Amberlite IRC-50 for the immobilization of lipase. It is considered to be the first of the peptide binding methods. Similarly, leucine amino peptide attached to the isocyanate derivative of fluorochrome was immobilized using $\mathrm{CNBr}$-activated sepharose.

II. Alkylation method (Tamer et al. 2016)

"This method involves the alkylation of amino, phenolic or sulphydryl groups of the enzyme protein with a reactive group (e.g., halide) in the water-insoluble carrier. Carriers possessing reaction halogens employed for the immobilization of enzyme are triazinyl derivative of cellulose, sephadex, sepharose, porous glass and bentonite. Enzymes such as aldolase glyceraldehyde phosphate dehydrogenase have been immobilized by using $A E$ cellulose and glutaraldehyde. Thiolation of enzymes containing no thiol group such as chymotrypsin and their subsequent immobilization through disulfide linkages has also been studied".

III. Diazo method (Tamer et al. 2016).

"This method involves the diazocoupling of the enzyme protein and diazonium derivatives of water-insoluble carriers. The functional groups participating in diazocoupling include free amino group imidazole group of histidine and phenolic group of lysine. For example, catalase is immobilized on m-aminoanisole cellulose and papain is 
immobilized on p-amino-DL-phenyl alanine, L-leucine".

2. Cross-linking method This method is based on the principle of formation of chemical bonds and intermolecular cross-linkages between the enzyme molecules by means of bifunctional and multifunctional reagents. Water-insoluble carriers are not used in this method. "Glutaraldehyde; isocyanate derivatives, bis-diazobenzelene. $N, N$-polyethylene, $N, N^{\prime}$-ethylene, bis-malomide have been in practice as cross-linking reagents. The functional groups of the enzyme protein participating in the reactions are $\alpha$ amino group or 3 -amino group of lysine, the phenolic group of tyrosine, sulfhydryl group of cystine and amindazole group of histidine. Severe conditions are required for the cross-linking of the enzymes. This results into the loss of activity due to change in the conformation of the active center of the enzyme. $N, N^{\prime}$ polymethylene bis-iodo-acetamide have been employed for the immobilization of the aldolase in rabbit muscle and $\alpha$ amylase, etc.

3. Entrapping method (Luna and Verdugo-Escamilla Online) "This method depends upon the principle of confining the enzyme in the lattice of a polymer matrix or enclosing it in a semi permeable membrane". The entrapping methods are of two types.

i. Lattice type This method involves "entrapping of the enzyme within the interstitial spaces of a cross-linked water-insoluble polymer, i.e., within the gel matrix. Various synthetic polymers such as polyacrylamide, polyvinyl alcohol and natural polymers such as starch, and konjac powder have been used for the immobilization of the enzyme by this method. This technique was used by Bernfeld et al. (1963) who entrapped trypsin, papain, amylase, ribonuclease, etc., in a gel lattice of polyacrylamide.

ii. Microcapsule type (Wikipedia) This method involves enclosing of enzyme within the semipermeable polymer membrane. The resulting enzyme microcapsules generally have a diameter of $1-100 \mu$. Microcapsules are being extensively used in medicine, foods, cosmetics, dyes and fuels. Extremely well controlled conditions are required for the enzyme preparation.

The procedures for the micro capsulation of the enzyme can be classified into three categories.

I. Interfacial polymerization (Okobira et al. 2015): "This procedure is based on the enclosing of the enzyme in a semi-permeable membrane of a poly- mer by applying the principle that hydrophobic and hydrophilic monomers polymerize the interface".

The micro-encapsulation of enzymes by this procedure was first reported by Chang et al. (2009); these workers microencapsulated asparaginase urease and carbonic anhydrase using a nylon membrane.

II. Phases separation method (Sun et al. 2017) This method is based on the principle of one of the purification methods for polymers. "It involves dissolving the polymer in an organic solvent and reprecipitating it by adding another organic solvent which is miscible with the first but which does not dissolve the polymer". Chang et al. (Online) succeeded in the microencapsulation of asparaginase, urease and catalase by this method. They also reported that more stable microencapsulated urease was obtained when the enzyme was microencapsulated after being adsorbed on silica gel.

III. Liquid membrane method (Kimura et al. 1989): In this method, "the encapsulation of enzymes by means of liquid membrane instead of a waterinsoluble semi-permeable membrane has been attempted. This new procedure involves encapsulation of the enzyme solution within an amphipathic liquid surfactant membrane (liposome), e.g., formed from surfactant and Lecithin. The most significant characteristic of liquid fraction microcapsules for the immobilization of glucoamylase is that the permeability of substrate and product across the liquid membranes is independent of pore size of membrane but depends on the solubility of the substrate and or product in the components of the membrane. Therefore, applications different from those of the conventional microcapsules are anticipated, and research on liquid membrane microcapsules is expected to increase in importance".

\section{Liquid drying method (Hossein et al. 2018)}

This method is based on the "enclosing of the enzyme via processes of dispersion in polymers dissolved in water immiscible organic solvents followed by dispersion in aqueous solution and subsequent drying. The microcapsulation of catalase, lipase and other enzymes have been carried out by this method using ethyl cellulose and polyethylene".

\section{Applications}

Immobilized enzymes have specific characteristics. Many efforts have been made to the development of immobilized enzymes for a number of applications. Their 
modified forms are applied in different fields as given below.

Synthesis of radioactive compounds

Analytical techniques

Medical treatments

Food processing such as hydrolysis of lactose before making milk fit for babies to drink, milk

Processing for removal of hydrogen per oxide from chemically sterilized milk using immobilized oxidase, production of cheese

Preparation of sweet liquor by hydrolysis of starch for continuous preprocessing of alcoholic fermentation using immobilized amylase from microorganisms instead of malt, Affinity chromatography

Fuel cells and bio-chemical batteries.

Sirisha et al. (1916) earlier reviewed the applications of immobilized enzymes and reported that the immobilized enzymes could be used in a wide range of processes. In recent years, a variety of new approaches have emerged for the immobilization of enzymes that have greater efficiency and wider usage. During the period of last two decades, this area has rapidly expanded into a multidisciplinary field.

This study is a comprehensive review of a variety of literature produced on the different enzymes that have been immobilized on various supporting materials and of the immobilized enzymes having a wide range of applications. These include applications in the sugar, fish, and wine industries, where they are used for removing organic compounds from waste water. This study also reviews their use in sophisticated biosensors for metabolite control and in situ measurement of environmental pollutants. Immobilized enzymes also find significant application in drug metabolism, biodiesel and antibiotic production, bioremediation, and the food industry. The widespread usage of immobilized enzyme technology is largely due to the fact that they are cheaper, environment friendly, and much easier to use when compared to other technologies.

Altikaynak et al. (2016) have reported that "many different micro and nano-sized materials can be used for enzyme immobilization in order to increase their catalytic activity and stability. Generally, immobilized enzymes with conventional immobilization techniques exhibit improved stability, while their activity is lowered compared to free enzymes". Recently, an excellent immobilization approach was discovered in synthesis of flowerlike organic-inorganic hybrid nanostructures with extraordinary catalytic activity and stability. In this novel immobilization strategy, "proteins (enzymes) and metal ions act as organic and inorganic components, respectively, to form hybrid nanoflowers (hNFs). It is demonstrated that the hNFs highly enhanced catalytic activities and stability in a wide range of experimental conditions: pHs, temperatures and salt concentration, etc. compared to free and conventionally immobilized enzymes". This review mainly discussed the synthesis, characterization, development and applications of organic-inorganic hybrid nanoflowers formed from different enzymes and metal ions and explained potential mechanism underlying enhanced catalytic activity and stability.

\section{Medical applications of immobilized enzymes}

The medical applications of immobilized enzymes have been extensively studied and developed and have been reviewed thoroughly by the author of the current review Khan (2021) and it may be fruitful for the seekers of detailed information about the medical applications to refer to his exercise. In his opinion, the enzymes immobilized by entrapping method particularly offer their therapeutic use in case of enzyme deficiency or metabolic disorders. He has outlined the attempts of major contributors in this context: Liang et al. (2000a) description of the medical applications of immobilized proteins, enzymes and cells. Examples are given below.

Microencapsulated catalase for enzyme replacement in acatalasemic mice

Use of liposomes for the microencapsulation of enzyme asparaginase and other enzymes in chemotherapy with reference to their use associated with problems related to toxicity.

Immunogenicity and duration of action

Lymphoma as the third most common cancer diagnosed in dogs.

Because of the importance of cancer treatment, many studies have been carried out using all available immobilization approaches. The immobilized enzymes are used in detoxification, because many of the detoxifying functions in the body are carried out by enzymatic reactions. Chang et al. (Online), for instance, investigated the application of enzymes microcapsules entrapped inside a semi-permeable poly membrane. Later workers prepared asparaginase microcapsule and attempted to use them for the treatment of leukemia (Lang et al. 2005; Harrer et al. 2007)". They also studied the changes of asparaginase level in blood after administration of asparaginase microcapsule.

Utilization of immobilized enzymes for the treatment of blood outside the body, i.e., "Extra Corporeal Shunt System" was attempted. Mori et al. (1972) investigated the application of immobilized asparaginase prepared by 
entrapping in poly acryl amide gel that is mechanistically stronger than the enzyme microcapsule for the therapy of leukemia by means of an extra corporeal shunt system. "This preparation was very stable towards the proteolytic enzymes and L-asparagin in blood was completely decomposed when blood was passed through a column packed with immobilized enzyme".

An extra corporeal shunt system is known to have great potential and may be applied for emergency cases. The time required for such a therapy can be controlled easily, and specific detoxicating material used for the system can be prepared readily.

An extra corporeal shunt system is known to have great potential and may be applied for emergency cases. The time required for such a therapy can be controlled easily, and specific detoxicating material used for the system can be prepared readily.

Liang et al. (2000a) presented a brief review of developments in use of immobilized enzyme in medicine. The panel divided the use of immobilized enzyme in medicine into two major categories: Biosensors and Bioreactors. A brief overview of the evolution of the biosensor and bioreactor technology pertaining to existing applications of immobilized enzymes at that time, of problems that researchers encountered, and of possible future developments were also highlighted.

Medical applications of immobilized proteins, enzymes and cells are also extensively encountered in the literature of Science Direct (Online).

The current research is mostly focused on the medical applications of immobilized microfluidic enzymatic reactors and biosensors for which the readers and reviewers may have the flashback to Khan's review article (2021) with many quotes in this context (Matosevic et al. 2011a, b; Khan and Talib 1986; Zhong 2007; Tischer and Wedekind 1999; Kawamura et al.; Kilbanov 1983; Science Direct, Rao Online, and others).

Different types of biosensors are in the market:

1. Electrochemical Biosensors....

2. Immunosensors

3. Magnetic Biosensors

4. Thermometric Biosensors

5. Acoustic Biosensors

6. Optical Biosensors

All these types are widely used. Reference list may be consulted for mechanics and uses of different types of biosensors.

As the focus is mainly on the use of immobilized enzymes as biosensors in bioreactors in pharmaceutical industry that manufactures drugs for the medical treatments, let us try to understand what these are? The bioreactor as defined in a Mini-Review on website (https://deepblue.lib.umich.edu/bitstream/handle/2027. 42/34503/2_ftp.pdf?sequence $=1$ ) as under:

Bioreactor is defined as a vessel that carries out a biological reaction and is used to culture aerobic cells for conducting cellular or enzymatic immobilization.

The cell culturing is the most commonly applied process in biopharmaceutical development, bioprocessing and bio-manufacturing in the pharmaceutical industry. Most biopharmaceutical products are developed from large, complex protein molecules grown in well-defined and highly controlled liquid environment, inside the bioreactors.

The performance of a bioreactor depends largely on biosensors that are defined as under:

"Biosensors are devices used to detect the presence or concentration of a biological analyte, such as a biomolecule, a biological structure or a microorganism" (Nature Online). A biosensor consists of three parts: a component that recognizes the analyte and produces a signal, a signal transducer, and a reading device. A biosensor is an analytical device, applied for the detection of a chemical substance, that combines a biological component with a physicochemical detector. The research related to biosensors is extensive and documented (Allen 1994; Bergamasco et al. 2000; Cabral et al. 2017; DeLoach and Droleskey 1993; Garin et al. 1995; Glaxier and McCurley 1995; Guerrieri et al. 1997; Hill et al. 1997; Horiuchi et al. 1997; Korpan et al. 1999; Lee et al. 2015; Li and Rosenzweig 1997; Liang et al. 2000b, 2011; Liu et al. 1997; Magnani et al. 1993; Marazuela et al. 1997; Marazuela and Moreno-Bondi 1998; Marzouk et al. 1999; Sirisha et al. 2016; Vidal et al. 1999).

\section{Conclusion}

From the points made in different sections, it may be concluded as under:

1. The chemistry and biology of immobilized enzymes are an important field in applied context, and thus, it will continue growing opening new vistas due to their future applications as biosensors and bioreactors, pharmaceuticals and industry in general.

2. The classification of immobilized enzymes may be revised to divide them into two major classes: naturally immobilized enzymes and artificially immo- 
bilized enzymes, while artificially immobilized enzymes may be sub-classified as done in 1971 .

3. The naturally immobilized enzymes can be used to hydrolyze proteins to prepare amino acids that can be used to prepare drips for instantaneous supply of nutrients to nutritionally deficient patients.

4. The immobilized enzymes can be filled in the dialyzers to remove poisons from the human blood particularly of the kidney patients.

\section{Abbreviations}

AcN: Acetonitrile; ATP: Adenosine triphosphate; CM: Carboxymethyl; NAD: Niacin adenine dinucleotide; DEAE: Diethylaminoethyl; DMSO: Dimethyl sulfoxide; DMFA: Dimethylformamide.

\section{Acknowledgements}

The author is extremely grateful to the Rector, Lahore School of Economics for the recognition of his multidisciplinary capability and sponsoring of his research in different fields.

\section{Authors' contributions}

Not applicable.

\section{Funding}

Not applicable.

Availability of data and materials

Not applicable.

\section{Declarations}

Ethics approval and consent to participate

Not applicable.

\section{Consent for publication}

Not applicable.

\section{Competing interests}

Not applicable.

Received: 10 June 2021 Accepted: 29 October 2021

Published online: 04 December 2021

\section{References}

Allen TM (1994) Long-circulating (sterically stabilized) liposomes for targeted drug delivery. Trends Pharmacol Sci 15:215-220

Altikaynak C, Tavlosoglu S, Yzdmir N, Oksoy I (2016) A new generation approach in enzyme immobilization: organic-inorganic hybrid nanoflowers with enhanced catalytic activity and stability. Enzyme Microb Technol 93-94:105-112

Atara BE, Katchaklaski A (1961) Water-insoluble trypsin derivative and its use as a trypsin column. Nature 188(4753):856-857

Bergamasco R, Bassetti FJ, De Moraes FF, Zanin GM (2000) Characterization of free and immobilized invertase regarding activity and energy of activation. Braz J Chem Eng 17(4):7

Bernfeld P, Wan J (1963) Antigens and enzymes made insoluble by entrapping them into lattices of synthetic polymers. Science 142(3593):678-679

Brena BN et al (2006) https://link.springer.com/protocol/10.1007\%2F978-159745-053-9_2n
Brena B, González-Pombo P, Batista-Viera F (2013) In: Immobilization of enzymes: a literature survey. Immobilization of enzymes and cells, pp. 15-31

Cabral BV, Santos LD, Larissa NS, Falleiros S, Taciana SC, Freitas FF, Cardoso SL (2017) Sucrose hydrolysis by invertase immobilized on Duolite A-568 employing a packed-bed reactor, pp 1007-1019

Campbell DH, Luescher E, Lerman LS (1951) Immunologic adsorbents: I. Isolation of antibody by means of a cellulose-protein antigen. Proc Nat Acad Sci U S A 37(9):575

Chang A, Scheer M, Grote A, Schomburg I, Schomburg D (2009) BRENDA, AMENDA and FRENDA the enzyme information system: new content and tools in 2009. Nucl Acid Res 37(suppl_1):D588-D592

Datta S, Christena LR, Rajaram YR (2013) Enzyme immobilization: an overview on techniques and support materials. 3 Biotech 3(1):1-9

DeLoach JR, Droleskey RE (1993) Endocytosis during the preparation of mouse and human carrier erythrocytes. Biotechnol Appl Biochem 18:83-92

Filipusson H, Hornby WE (1970) The preparation and properties of yeast beta-fructofuranosidase chemically attached to polystyrene. Biochem $J$ 129:215-219

Freeman A, Lilly MD (1998) Effect of processing parameters on the feasibility and operational stability of immobilized viable microbial cells. Enzyme Microb Technol 23:315-345

Fu J, Reinhold J, Woodbury NW (2011) Peptide-modified surfaces for enzyme immobilization. PLoS ONE 6(4):1869

Garin M, Rossi L, Luque J, Magnani M (1995) Lactate catabolism by enzymeloaded red blood cells. Biotechnol Appl Biochem 22:295-303

Glaxier SA, McCurley MF (1995) Biosensor applications for bioprocess monitoring and drug analysis. Biopharmacology 8:38-48

Godbole SS, D'souza SF, Nadkarni GB (1980) Immobilization of alcohol dehydrogenase by gel entrapment of cells of Saccharomyces cerevisiae. Enz Microbial Technol 2(3):223-226

Goldstein L, Levin Y, Katchalski E (1964) anionic glucoamylase was modified to a polynomic derivative by covalent binding with a water soluble polymer of ethylene and maleic anhydride. Biochemistry 3(12):1913-1919

Grubhofer N, Schleith L (1953) Modified ion exchangers as specific adsorbents. Naturwissenschaften 40:508-512

Guerrieri A, Debenedetto GE, Palmisanso F, Zambonin F, Zambonin PG (1997) A fiber optic sensor for rapid analysis of bilirubin in serum. Anal Chim Acta 353:263-273

Handbook of biofuels production, 2nd edn

Harrer T, Geißdörfer W, Schoerner C et al (2007) Seronegative lyme neuroborreliosis in a patient on treatment for chronic lymphatic leukemia. Infection 35:110. https://doi.org/10.1007/s15010-007-6121-0

Hartmeier W (2016) Immobilized biocatalysts. Springer, An introduction methods of immobilization immobilized biocatalysts

Hassan ME, Yang Q, Xiao Z (2019) Covalent immobilization of glucoamylase enzyme onto chemically activated surface of $\mathrm{k}$-carrageenan. Bull Natl Res Centre 43(1):1-11

Hill KJ, Kaszuba M, Creeth JE, Jones MN (1997) Reactive liposomes encapsulating a glucose oxidase-peroxidase system with antibacterial activity. Briochem Biophys Acta 1326:37-46

Homaei AA, Sariri R, Vianello F, Stevanato FR (2013) Enzyme immobilization: an update. J Chem Biol 6(4):185-205

Horiuchi T, Torimitsu K, Yamamoto K, Niwa O (1997) On-line flow sensor for measuring acetylcholine combined with microdialysis sampling probe. Electroanalysis 9:912-916

Hossein SH, Hosseini SA, Zohreh N, Yaghoubi M, Pourjavad A (2018) Covalent Immobilization of cellulase using magnetic poly(ionic liquid) support: improvement of the enzyme activity and stability. J Agric Food Chem 66(4):789-798. https://doi.org/10.1016/B978-0-12-041104-7.50007-5

Jesionowski T, Zdarta J, Krajewska B (2014) Enzyme immobilization by adsorption: a review. Adsorption 20:801-821. https://doi.org/10.1007/ s10450-014-9623-y

Katzir-Katchalski E, Kraemer DM, Eupergit RC (2000) A carrier for immobilization of enzymes of industrial potential. J Mol Catal B Enzym 10(1-3):157-176

Khan MR (2021) Current and future role of immobilized enzymes in medical field. Curr Med Drug Res 5(1):1-9

Khan MR, Bukhari H (2008a) Immobilization of the protease of Carica papaya on activated charcoal. Asian J Chem 20(8):5782-5788 
Khan MR, Bukhari H (2008b) Continuous proteolysis of casein by cell bound protease of Carum copticum. Asian J Chem 20(7):5729-5735

Khan MR, Talib A (1986) Immobilization of protease of Calotropis procera. Pak Sci Ind Res 2(4):259-262

Khan MR, Imran RM, Bukhari H (2008) Continuous proteolysis of casein by the cell bound protease of Carum copticum. Asian J Chem 20(7):5729-5735

Kilbanov AM (1983) Immobilized enzymes and cells as practical catalysts. Science 219(4585):722-727

Kimura J, Kawana Y, Kuriyama T (1989) An immobilized enzyme membrane fabrication method using an ink jet nozzle. Biosensors 4(1):41-52

Korpan Yl, Arkhipova VN, Alesina MY, Martelet C, El'Skaya AV, Soldatkin AP (1999) Application of enzyme field-effect transistors for determination of glucose concentrations in blood serum. Biosens Bioelectron 14:283-287

Krishnamoorthi S, Banerjee A, Roychoudhur A (2015) Immobilized enzyme technology: potentiality and prospects. J Enzymol Metab 1(1):104

Lang K, Earle CC, Foster T, Dixon D, Van Gool R, Menzin J (2005) Trends in the treatment of acute myeloid leukaemia in the elderly. Drugs Aging 22(11):943-955

Lee J, Bagheri B, Kao HA (2015) A cyber-physical systems architecture for industry 4.0-based manufacturing systems. Manufact Lett 3:18-23

Levitsky V, Lozano P, Gladilin AL (1998) Stability of immobilized enzyme-polyelectrolyte complex against irreversible inactivation by organic solvents. Prog Biotechnol 15:417-422

Li XP, Rosenzweig Z (1997) A fiber optic sensor for rapid analysis of bilirubin in serum. Anal Chim Acta 353:263-273

Liang JF, Li YT, Yang VC (2000a) Biomedical application of immobilized enzymes. J Pharm Sci 89(8):979-90

Liang JF, Yong TL, Yang VC (2000b) Biomedical application of immobilized enzymes. J Pharm Sci 89(8):979-990

Liang JF, Yong TL, Yang VC, Other Participants of Overlay Panel (2011) Biomedical application of immobilized enzymes. In: Matosevic S, Szita N, Banganz $F$ (eds) Fundamentals and applications of immobilized microfluidic enzymatic reactors (online)

Liu DZ, Kai G, Kang C, Ni LH, Yao SZ (1997) A highly sensitive amperometric creatinine sensor. Anal Chim Acta 351:151-158

Lowe CR (1977) Immobilized lipoamide dehydrogenase: properties of the enzyme immobilized to agarose through spacer molecules of various lengths. Eur J Biochem 76:401-409

Magnani M, Fazi A, Mangani F, Rossi L, Mancini U (1993) Methanol detoxification by enzyme-loaded erythrocytes. Biotechnol Appl Biochem 18:217-226

Marazuela MD, Moreno-Bondi MC (1998) Determination of choline-containing phospholipids in serum with a fiber-optic biosensor. Anal Chim Acta 374:19-29

Marazuela MD, Cuesta B, Moreno Bondi MC, Quejido A (1997) Free cholesterol fiber-optic biosensor for serum samples with simplex optimization. Biosens Bioelectron 12:233-240

Markoglou N, Wainer H (2003) Immobilized enzyme reactors in liquid chromatography: on-line bioreactors for use in synthesis and drug discovery. In: Wilson ID (ed) Handbook of analytical separations, Chapter 7, pp 214-234

Marzouk SAM, Cosofret WV, Buck RP, Yang H, Cascio WE, Hassan SSM (1999) A disposable biosensor for urea determination in blood based on an ammonium-sensitive transducer. Biosens Bioelectron 14:33-41

Matosevic S, Szita N, Banganz F (2011a) Fundamentals and applications of immobilized microfluidic enzymatic reactors. J Chem Technol Biotechnol 86(3):325-34

Matosevic S, Szita N, Banganz F (2011 b) Fundamentals and applications of immobilized microfluidic enzymatic reactors. Chem Technol Biotechnol. https://doi.org/10.1002/jctb.2564

Mitz MA (1956) New insoluble active derivative of an enzyme as a model for study of cellular metabolism. Science 123(3207):1076-1077

Mohamad NR, Che-Marzuki H, Nor Aziah Buang NA, Huyop F, Wahab RA (2015) An overview of technologies for immobilization of enzymes and surface analysis techniques for immobilized enzymes. Biotechnol Biotechnol Equip 29(2):205-220

Mori T, Sato T, Tosa T, Chibata I (1972) Studies on immobilized enzymes. X. Preparation and properties of aminoacylase entrapped into acrylamide gel-lattice. Enzymologia 43(4):213-226

Micheel VF, Ewers J (1949) Synthese von verbindungen der cellulose mit eiweißstoffen. Die Makromol Chem: Macromol Chem Phys 3(1):200-209

Nature Research, Biosensors https://www.nature.com/subjects/
Nawaz SA, Khan MR (2000) Immobilization of the proteases of Eurphorbia royleana. Pak J Biol Sci 39(12):2210-2212

Nelson JM, Griffin EG (1916) Adsorption of invertase. J Am Chem Soc 38(5):1109-1115

Okobira T, Matsumoto AH, Tanaka T, Kai K, Minari C, Goto M, Kawakita H (2015) Uzu K (2015) Enhancement of immobilized lipase activity by design of polymer brushes on a hollow fiber membrane. J Biosci Bioeng 120(3):257-262

Rani K (2012) Brief introduction on enzyme immobilization (online). https:// www.biotecharticles.com/Applications-Article/BRIEF-INTRODUCNTIONON-ENZYME-IMMOBILIZATION-1510.html

Sato T, Tosa T (2002) Enzymes, immobilization methods. Encyclopedia of Bioprocess Technology: Fermentation, Biocatalysis, and Bioseparation.

Science Direct (1978) Chapter 12 Immobilized enzymes. J Chromatogr Library 12: $365-386$

Science Direct. https://www.sciencedirect.com/topics/agricultural-and-biolo gical-sciences/immobilized-enzymes-

Singh RK, Tiwari MK, Singh R, Lee JK (2013) From protein engineering to immobilization: promising strategies for the upgrade of industrial enzymes. Int J Mol Sci 14(1):1232-1277

Sirisha VL, Jain A, Jain A (2016) Advances in food and nutrition research vol 79, pp 179-211

Sumner JB (1946) The Nobel Lecture, December 12

Sun X, Xin Y, Wang X, Uyama H (2017) Functionalized acetoacetylated poly(vinyl alcohol) monoliths for enzyme immobilization: a phase separation method. Colloid Polym Sci 295:1827-1833

Suzuki H, Ozawa Y (2014) Studies on the water-insoluble enzyme, hydrolysis of sucrose by insoluble yeast invertase. Agric Biol Chem 30(8):1966. https:// doi.org/10.1080/00021369.1966.10858683

Tamer TM, Omer AM, Hassan M (2016) Methods of enzyme immobilization. Int J Curr Pharm Rev Res 7(6):385-392

Tischer W, Wedekind F (1999) Immobilized enzyme: methods and applications. Biocatal Discov Appl 66:95-126. https://doi.org/10.1007/3-540-68116-7 4

Tosa T, Mori T, Fuse N, Chibata F (1969a) Studies on continuous enzyme reactions, Part V. Kinetics and industrial applications of aminoacyl column for continuous optical resolution of acyl amino-acids. Agric Biol Chem 33:1017-1052

Tosa T, Mori T, Fuse N, Chibata I (1969b) Studies on Continuous Enzyme Reactions: Part V. Kinetics and industrial application of aminoacylase column for continuous optical resolution of Acyl-dl-Amino acidsPart VI. Enzymatic properties of the DEAE-Sephadex-Aminoacylase complex. Agric Biol Chem 33(7):1047-1059

Vidal MM, Gil MH, Delgadillo I, Alonso J, Dzyadevich SV (1999) Study of thermal stability and enzymatic stability of an immobilized enzymatic system for a bilirubin oxidation. Biomaterials 20:757-763

Waterhouse DS, Waterhouse GIN (2020) Recent approaches of nanotechnology in food. Volume 1 Novel approaches of recent advances in the application of nanomaterials and nanotechnology in food research Volume 2. Science Direct

Wikipedia https://en.wikipedia.org/wiki/Micro-encapsulationa

Zdarta J, Meyer AS, Jesionowksi T, Pinelo M (2018) A general overview of support materials for enzyme immobilization: characteristics, properties and practical utility, catalyst. MDPI file:///C:/Users/Dr\%20Rafiq/Downloads/ catalysts-08-00092.pdf

Zhong J (2007) Bioprocessing for value-added products from renewable resources. https://www.sciencedirect.com/topics/neuroscience/biore actors

Zhong DH, Li YQ, Peng LJ, Chen N (2014) Lipase immobilization on magnetic microspheres via spacer arms: effect of steric hindrance on the activity. Biotechnol Bioprocess Eng 19:838-843

\section{Publisher's Note}

Springer Nature remains neutral with regard to jurisdictional claims in published maps and institutional affiliations. 